\title{
Pregnancy outcome in women with congenital heart disease in a tertiary care centre
}

\author{
Lipika Adhikari, Sandip Sarkar, Amitava Das, Priyanka Sannigrahi, Prateek Chawdhary \\ Correspondence: Sandip Sarkar, Assistant Professor, Department of Obstetrics and \\ Gynaecology, R G Kar Medical college, Kolkata, West Bengal, India. Email - \\ sandip.chinsurah@gmail.com
}

Distributed under Creative Commons Attribution-Share Alike 4.0 International.

\begin{abstract}
Objective: To find out prevalence of congenital heart disease in pregnant women and its cardiac, obstetric and neonatal outcome. Methodology: A prospective study was conducted on 74 mothers who had congenital heart disease and admitted in Obstetrics and Gynaecology department during a period of December 2013 to December 2017. Baseline data were collected before pregnancy or at the first antenatal visit. These included clinical presentation, ECG, chest X ray, echodoppler study and subsequently maternal cardiac event, obstetric outcome, neonatal event and risk stratification of bad obstetric outcome. Result: During the study period 74 women having congenital heart disease (CHD) were seen. The prevalence of congenital heart disease was $0.14 \%$. Most of the patients had atrial septal defect (ASD) (35\%). Normal delivery was in 18 numbers of patients and most of these were ASD and pulmonary stenosis. Large number of patients had developed complication of sustained arrhythmia (41\%). Pulmonary oedema was documented in 8 patients. Seven patients expired during labour and puerperium. Regarding fetal outcome 58\% pregnancy had intrauterine growth restriction, $67 \%$ had preterm birth and $8 \%$ had neonatal death. Conclusion: Maternal and neonatal complication rates are considerably high in pregnant women with congenital heart disease.
\end{abstract}

Keywords: Congenital heart disease, arrhythmia, congestive cardiac failure, cyanotic heart

disease.

Routine health screening in school going children, relevant referral for cardiological evaluation and treatment of congenital heart disease have enabled increasing number of women surviving into their child bearing age. Cardiac output increases by $30-50 \%$ during pregnancy and a further increase during labour and delivery imposes burden on diseased heart leading to complications and death ${ }^{1-3}$. Prevalence of heart disease in pregnancy varies from $0.3-3.5 \%$ and cardiac disorders contribute to approximately $20 \%$ of maternal death ${ }^{4,5}$.
The diagnosis of congenital heart disease preferably before or at least at first antenatal visit is crucial for decision regarding safe continuation of pregnancy or termination, for giving intensive medical/interventional care during perinatal period and planning the mode of delivery. Present study was adopted to find out the type of congenital heart disease and their pregnancy outcome.

\section{Materials and Methods}

A total of 74 pregnant women having congenital heart disease, already diagnosed and treated or newly diagnosed

Received: $20^{\text {th }}$ December 2017. Accepted: $21^{\text {st }}$ January 2018.

Adhikari L, Sarkar S, Das A, Sannigrahi P, Chawdhary P. Pregnancy outcome in women with congenital heart disease in a tertiary care centre. The New Indian Journal of OBGYN. 2018; 5(1): 38-42. 
for the first time in pregnancy, admitted to obstetric ward of RG Kar MCH from December 2013 to December 2017 were included in the study. Baseline data included age, gestational age, type of congenital heart disease, time of diagnosis, already operated or not, definite corrective surgery or palliative surgery, present New York Heart Association (NYHA) functional class, oxygen saturation, maternal complications, mode of delivery and neonatal outcome. Routine complete cardiological evaluation by clinical examination, electrocardiogram (ECG) and echodoppler study was done at first visit. Detail records of previous cardiological evaluation and treatment was also collected.

Cardiac events like decline in NYHA functional class, pulmonary oedema, arrhythmia, stroke and cardiac arrest or sudden cardiac death, obstetric events like preeclampsia, postpartum haemorrhage, puerperal venous thromboembolism and neonatal events like preterm delivery, respiratory distress syndrome, foetal or neonatal death were observed and tabulated. Patients with rheumatic heart disease, hypertensive heart disease, ischemic heart disease and peripartum cardiomyopathy were excluded from the study. Statistical analysis data obtained was collected and analyzed statistically by percentage, proportions.

\section{Results}

A total of 74 pregnant women with congenital heart disease were included in the study. Total number of

Table 1: Demographic characteristics $(\mathrm{N}=74)$

\begin{tabular}{cc}
\hline Characteristics & No (\%) \\
\hline Age(years) & $21(34 \%)$ \\
$18-22$ & $48(60 \%)$ \\
$23-27$ & $05(06 \%)$ \\
$>28$ & \\
Gravida & $62(78 \%)$ \\
Primigravida & $12(22 \%)$ \\
Multigravida & \\
Time of diagnosis & $21(35 \%)$ \\
Before pregnancy & $53(65 \%)$ \\
After pregnancy & \\
Time of delivery & $50(67 \%)$ \\
Preterm & $24(33 \%)$ \\
Term & \\
I and II & $48(65 \%)$ \\
III and IV & $26(35 \%)$ \\
\hline
\end{tabular}

delivery during the mentioned study period was 54,124. Hence the prevalence of congenital heart disease in our institution was $0.14 \%$. Majority of the patients were

Table 2: Distribution of congenital heart disease (N=74)

\begin{tabular}{lc}
\hline Congenital lesion & No (\%) \\
\hline Atrial septal defect & $26(35 \%)$ \\
Surgically repaired & $04(05 \%)$ \\
Unoperated & $22(29 \%)$ \\
Ventricular septal defect & $05(07 \%)$ \\
Surgically repaired & $01(02 \%)$ \\
Unoperated & $04(05 \%)$ \\
Patent ductus arteriosus & $09(12 \%)$ \\
Surgically repaired & $02(03 \%)$ \\
Unoperated & $07(09 \%)$ \\
Primary pulmonary hypertension & $02(03 \%)$ \\
Pulmonary stenosis & $14(19 \%)$ \\
After balloon valvotomy & $08(11 \%)$ \\
Untreated & $06(08 \%)$ \\
Tetralogy of Fallot & $10(14 \%)$ \\
Repaired & $02(03 \%)$ \\
Unrepaired & $08(11 \%)$ \\
Unoperated CCTGA & $02(04 \%)$ \\
DORV VSD PS & $02(01 \%)$ \\
Ebstein anomaly & $04(03 \%)$ \\
\hline CCTGA - Congenitally corrected transposition of great \\
arteries; DORV - Double outlet right ventricle; VSD - \\
Ventricular septal defect; PS - Pulmonary stenosis.
\end{tabular}

primigravida and in the age group $23-27$ years (Table 1). Most of the patients had atrial septal defect $(35 \%)$ followed by pulmonary stenosis (19\%) and tetralogy of

Table 3: Mode of delivery $(\mathrm{N}=74)$

\begin{tabular}{ccc}
\hline $\begin{array}{c}\text { Congenital heart } \\
\text { disease }\end{array}$ & $\begin{array}{c}\text { Caesarean } \\
\text { section }\end{array}$ & $\begin{array}{c}\text { Vaginal } \\
\text { delivery }\end{array}$ \\
\hline ASD & 16 & 10 \\
VSD & 04 & 01 \\
PDA & 08 & 01 \\
PPH & 02 & 00 \\
PS & 08 & 06 \\
TOF & 10 & 00 \\
CCTGA & 02 & 00 \\
DORV VSD PS & 02 & 00 \\
Ebsteine anomaly & 04 & 00 \\
\hline \multicolumn{2}{c}{ PDA - Patent Ductus Arteriosus } \\
\hline
\end{tabular}

fallot (TOF) (14\%). Two severe pulmonary stenosis patients underwent balloon pulmonary valvotomy at 12 weeks of gestation and subsequent maternal and fetal 
outcome was excellent (Table 2). Out of 74 pregnancies, term normal delivery was in 18 and most of these patients

\begin{tabular}{lc}
\multicolumn{2}{l}{ Table 4: Cardiac, obstetrics and neonatal outcomes } \\
\hline Categories & No (\%) \\
\hline Maternal cardiac complications & $8(11 \%)$ \\
Pulmonary edema & $30(41 \%)$ \\
Sustained arrhythmia & $01(01 \%)$ \\
Ceribrovascular accident & $07(09 \%)$ \\
Cardiac death & \\
Obstetric complications & $08(11 \%)$ \\
Preeclampsia & $12(16 \%)$ \\
Postpartum haemorrhage & \\
Neonatal complications & $50(67 \%)$ \\
Preterm baby & $43(58 \%)$ \\
Fetal growth restriction & $42(57 \%)$ \\
Respiratory distress & $03(04 \%)$ \\
Intrauterine foetal death & $07(08 \%)$ \\
Neonatal death &
\end{tabular}

were ASD/PS. The rate of caesarean section was significantly higher in women with CHD. Caesarean section was performed in $75.67 \%$ of pregnancies in women with CHD (Table 3). Small ASD, restrictive or moderately restrictive VSD/PDA had favourable pregnancy, cardiac and neonatal outcome. But mother with large non-restrictive shunts developed deterioration of NYHA functional class or frank pulmonary oedema $(\mathrm{N}=8)$. Large number of patients had sustained arrhythmia (41\%) and one patient developed massive embolic stroke. Atrial fibrillation developed in ASD, PDA, CCTGA and Ebsteine anomaly patient. Two patients developed supraventricular tachycardia, one with Ebsteine anomaly and another with CCTGA. Ventricular tachycardia (VT) developed in 10 patients out of which 2 were operated TOF mother. Two of the VT patients expired due to VT storm. Out of seven cardiac deaths, two TOF mother died due to ventricular tachycardia storm and three TOF, one DORV VSD PS and one Ebsteine anomaly mother expired due to congestive cardiac failure.

Preterm and intra uterine growth restriction (IUGR) babies were born in mothers with stenotic valvular heart disease and cyanotic heart disease. Mother with significant shunt lesion had IUGR babies $(\mathrm{N}=22)$ and premature delivery $(\mathrm{N}=9)$. Five Eissenmenger mother had spontaneous abortion at $10^{\text {th }}$ week of gestation. Cyanotic heart disease patients had high foetal mortality $(\mathrm{N}=7)$. Intra uterine fetal death (IUFD) was more in
Eissenmenger syndrome, cyanotic heart disease and primary pulmonary hypertension. Six moderate valvular pulmonary stenosis mothers gave birth of healthy baby and maternal outcome remained uneventful.

Patients with prior history of heart failure, advanced NYHA functional class, cardiomegaly, cyanosis and arrhythmia are risk factors for adverse outcome.

\section{Discussion}

Cardiovascular changes in pregnancy includes decreased systemic and pulmonary vascular resistance, increased heart rate, increased plasma volume therefore decreased packed cell volume/colloid osmotic pressure, increased end diastolic volume and cardiac output, third heart sound and ejection systolic murmur ${ }^{9,10,20}$. Predictors of poor pregnancy outcome are NYHA III or IV before pregnancy, saturation $<90 \%$ on air, left heart obstruction, previous cardiac event, systemic ventricular ejection fraction $<40 \%$, depressed right ventricular systolic function and symptomatic arrhythmia ${ }^{11,12,19}$. Hence excess preload in pregnancy precipitates pulmonary oedema and congestive cardiac failure, reduced systemic vascular resistance increases right to left shunt and thus aggravates cyanosis, increases the risk of paradoxical embolism ${ }^{13,18}$. So, normal physiological changes that facilitates good fetal and maternal outcome, becomes detrimental for mothers with heart disease. Our target in this situation is to address these changes in time.

Severity of CHD and heart function was analyzed as possible predictors for mode of delivery and pregnancy outcome. Indications for caesarean sections were differentiated into cardiac, obstetric and other reasons. Cardiac reasons were defined as "poor heart function" and "worsening of heart function", respectively. Obstetric reasons were defined as "fetal safety reasons" and, in the case of secondary caesarean sections, "failure to progress in labor". The rate of primary caesarean section, defined as "Planned Caesarean Section", as well as the rate of secondary caesarean section, defined as "Caesarean section following spontaneous onset of labor/failed attempted vaginal delivery", was higher in women with $\mathrm{CHD}^{6-8,21}$. Similar findings were observed in this study where caesarean section was performed in $76 \%$ of pregnancies in women with CHD.

Certain congenital heart diseases are still associated with a high maternal mortality. Women with the 
The New Indian Journal of OBGYN. 2018 (July-December); 5(1)

following should be advised against pregnancy i.e aortic stenosis peak gradient $>50 \mathrm{~mm} \mathrm{Hg}$, Marfan syndrome with aortic root $>5 \mathrm{~cm}$, Eisenmenger syndrome, Arterial switch operation ${ }^{14,15}$. The following are indications for elective caesarean section i.e. repaired coarctation of the aorta, warfarin within two weeks, Eisenmenger syndrome and dilated aortic $\operatorname{root}^{16,17,23}$. Management by an experienced team in a designated specialist centre with a high dependency unit solves majority of the problems and thus improves pregnancy outcome.

\section{Conclusion}

Small ASD, restrictive or moderately restrictive VSD/PDA had favourable pregnancy, cardiac and neonatal outcome. Cyanotic heart disease patients had high feto-maternal morbidity and mortality. It is also important to remember that inappropriate advice against pregnancy for a minor lesion is not desired. The challenge to the cardiologist, obstetrician, and anaesthetist working as a team is to face the most realistic and comprehensible estimate of risk, both fetal and maternal. Advances in paediatric cardiology and cardiac surgery are resulting in a growing population of young women with congenital heart disease well enough to contemplate pregnancy.

\section{Conflict of interest: None. Disclaimer: Nil.}

\section{References}

1.Perloff JK. Congenital heart disease in adults. A new cardiovascular subspecialty. Circulation. 1991; 84:1881-90.

2.Wren C, O'Sullivan JJ. Survival with congenital heart disease and need for follow up in adult life. Heart. 2001; 85: $438-43$.

3.Pitkin RM, Perloff JK, Koos BJ, et al. Pregnancy and congenital heart disease. Ann Intern Med 1990;112: 445-54.

4.Nelson-Piercy C. Heart disease. In: Handbook of obstetric medicine. 2nd ed. London: Martin Dunitz, 2002: 22-4

5.Canobbio MM, Mair DD, van der Velde M, et al. Pregnancy outcomes after the Fontan repair. J Am Coll Cardiol. 1996; 28: 763-7.

6.Presbitero P, Somerville J, Stone S, et al. Pregnancy in cyanotic congenital heart disease. Outcome of mother and fetus. Circulation. 1994; 89: 2673-6.

7.Yentis SM, Steer PJ, Plaat F. Eisenmenger's syndrome in pregnancy: maternal and fetal mortality in the $1990 \mathrm{~s}$. Br J Obstet Gynaecol. 1998; 105: 921-2.
8.Lalchandani S, Wingfield M. Pregnancy in women with Marfan's syndrome. Eur J Obstet Gynecol Reprod Biol. 2003; 110: 125-30.

9.Immer FF, Bansi AG, Immer-Bansi AS, et al. Aortic dissection in pregnancy: analysis of risk factors and outcome. Ann Thorac Surg. 2003; 76: 309-14.

10.Weiss BM, Hess OM. Pulmonary vascular disease and pregnancy: current controversies, management strategies, and perspectives. Eur Heart J. 2000; 21: 104-15.

11.Silversides CK, Colman JM, Sermer M, et al. Early and intermediate-term outcomes of pregnancy with congenital aortic stenosis. Am J Cardiol. 2003; 91: 1386-9.

12.Longo LD. Maternal blood volume and cardiac output during pregnancy: a hypothesis of endocrinologic control. Am J Physiol. 1983; 245 (pt 1): R720-R729.

13. Mone SM, Sanders SP, Colan SD. Control mechanisms for physiological hypertrophy of pregnancy. Circulation. 1996; 94: 667-72.

14.Robson SC, Hunter S, Boys RJ, Dunlop W. Serial study of factors influencing changes in cardiac output during human pregnancy. Am J Physiol. 1989; 256 (pt 2): H1060 H1065.

15.Campos O. Doppler echocardiography during pregnancy: physiological and abnormal findings. Echocardiography. 1996; 13: 135-46.

16.Hijazi ZM, Hellenbrand WE. The right ventricle in congenital heart disease. Cardiol Clin. 1992; 10: 91-110.

17.Fogel MA, Rychik J. Right ventricular function in congenital heart disease: pressure and volume overload lesions. Prog Cardiovasc Dis. 1998; 40: 343-56.

18.Redington AN. Right ventricular function. Cardiol Clin. 2002; 20: 341-49.

19.Chadwick RS, Azancot-Benisty A, Ohayon J, Ito Y. Right and left ventricle interaction and remodeling in congenital heart disease. Adv Exp Med Biol. 1993; 346: 373-81.

20.Hoffman D, Sisto D, Frater RW, Nikolic SD. Left-to-right ventricular interaction with a noncontracting right ventricle. J Thorac Cardiovasc Surg. 1994; 107: 1496-1502.

21.Dickstein ML, Todaka K, Burkhoff D. Left-to-right systolic and diastolic ventricular interactions are dependent on right ventricular volume. Am J Physiol. 1997; 272 (pt 2): H2869-H2874.

22.Pinsky MR, Perlini S, Solda PL, Pantaleo P, Calciati A, Bernardi L. Dynamic right and left ventricular interactions in the rabbit: simultaneous measurement of ventricular pressure-volume loops. J Crit Care.1996; 11: 65-76. 
The New Indian Journal of OBGYN. 2018 (July - December); 5(1)

23.Brookes C, Ravn H, White P, Moeldrup U, Oldershaw P, Redington A. Acute right ventricular dilatation in response to ischemia significantly impairs left ventricular systolic performance. Circulation. 1999; 100: 761-67.

Lipika Adhikari ${ }^{1}$, Sandip Sarkar ${ }^{2}$, Amitava Das $^{3}$, Priyanka Sannigrahi ${ }^{4}$, Prateek Chawdhary ${ }^{5}$
${ }^{1}$ Assistant Professor, ${ }^{3}$ Professor, ${ }^{4}$ Post Graduate Trainee, Department of Obstetrics and Gynaecology, R G Kar Medical college, Kolkata, West Bengal, India; ${ }^{2}$ Assistant Professor, 5Post Graduate Trainee, Department of Cardiology, R G Kar Medical college, Kolkata, West Bengal, India. 